\title{
Penerapan Kombinasi Metode Simple Additive Weighting (SAW) dan Rank Order Centroid (ROC) dalam Keputusan Pemberian Kredit
}

\author{
Silvi Lestari \\ Prodi Manajemen Informatika, AMIK Kosgoro, Padang, Indonesia \\ Email: randanghjfatimah@gmail.com
}

\begin{abstract}
Abstrak
Pemberian Kredit merupakan suatu proses yang sangat penting bagi manajer kredit. Salah didalam menghasilkan keputusan bagi penerima kredit akan berakibat gagalnya dalam pembayaran tagihan kredit. Agar keputusan yang diberikan oleh manajer kredit menjadi lebih tepat, maka dibutuhkan sistem pendukung keputusan (SPK) dalam perhitungannya. Pada penelitian ini, penulis menggunakan kombinasi metode Rank Order Centroid (ROC) dan Simple Additive Weighting (SAW) dalam menghasilkan nilai preferensi akhir yang berguna dalam perangkingan keputusan penilaian calon nasabah kredit yang diterima. Hasil penelitian akan memberikan nilai akhir yang dapat membantu manajer kredit dalam efektifitas keputusan penerima kredit.
\end{abstract}

Kata Kunci: ROC, SAW, Simple Additive Weighting, Kredit, Rank Order Centroid

\section{Abstract}

Lending is a very important process for credit managers. Incorrect in making decisions for credit recipients will result in failure in payment of credit bills. In order for decisions made by credit managers to be more precise, a decision support system (DSS) is needed in their calculations. In this study, the authors used a combination of Rank Order Centroid (ROC) and Simple Additive Weighting (SAW) methods in producing final preference values that are useful in ranking the judicial decisions of potential credit customers. The results of the study will provide the final value that can help credit managers in the effectiveness of credit recipient decisions.

Keywords: ROC, SAW, Simple Additive Weighting, Credit, Rank Order Centroid

\section{PENDAHULUAN}

Penetapan pemberian kredit kepada seorang nasabah merupakan suatu yang sangat penting bagi manager kredit. Pemberian kredit yang tepat sasaran kepada seorang nasabah dapat mengurangi kegagalan nasabah dalam proses pembayaran tagihan kredit kedepannya. Agar keputusan pemberian kredit tepat sasaran, maka manager kredit harusnya menggunakan aplikasi pendukung keputusan berbasis komputer yang dikenal dengan istilah sistem pendukung keputusan (SPK)[1].

Sistem Pendukung Keputusan (SPK) merupakan sistem berbasis komputer yang dapat membantu manager dalam pengambilan keputusan baik bersifat terstruktur maupun tidak terstruktur. Manager perusahaan ataupun pimpinan suatu perusahaan dalam aktifitasnya tidak terlepas dari adanya keputusan yang dihasilkan. Agar keputusan yang dihasilkan terbebas dari subjektifitas diperlukan sistem pendukung keputusan[2]-[4].

Beberapa penelitian yang dilakukan oleh beberapa peneliti sangat dirasakan manfaat yang besar sekali dengan penggunaan SPK, seperti yang dilakukan oleh Imam Saputra (2017), untuk pemilihan kulkas terbaik dengan penerapan menggunakan metode ELECTRE. Hasil penelitian diperoleh, bahwa tahapan tahapan pada metode tersebut mampu memberikan hasil preferensi yang sangat baik dalam menghasilkan pemeringkatan terhadap kulkas terbaik[5]. Penelitian selanjutnya dilakukan oleh Mesran (2019) dengan mengkombinasikan metode ROC dan ARAS dalam penilaian efektifitas kinerja karyawan. Mesran mengemukakan bahwa kombinasi metode Rank Order Centroid memberikan hasil pembobotan yang signifikat dalam perolehan preferensi kinerja karyawan, bila dibandingkan tanpa menggunakan metode pembobotan[6].

Hingga saat ini banyak metode yang sudah digunakan peneliti dalam penerapan pendukung keputusan dengan menggunakan SPK, diantaranya Simple Additive Weighting (SAW)[7]-[9], ELECTRE [10], EXPROM 2 [11]-[13], AHP[14], [15] dan lainnya. Dari penjelasan diatas maka penulis mencoba untuk mengkombinasikan metode Simple Additive Weighting (SAW) dengan metode Rank Order Centroid(ROC) dalam penentuan pemberian kredit bagi nasabah. Hal ini bertujuan agar hasil pembobotan yang didapat dari metode ROC signifikan dalam perhitungan preferensi yang dilakukan oleh metode SAW.

\section{METODE PENELITIAN}

\subsection{Kredit}

Kredit dapat diartikan yaitu penyediaan uang/tagihan yang dapat dipersamakan dengan itu berdasarkan persetujuan/kesepakatan pinjam-memimjam antara pihak bank dengan pihak lain yang mewajibkan pihak peminjam untuk melaksanakan dengan jumlah bunga sebagai imbalan. 


\subsection{Rank Order Centroid(ROC)}

Metode Rank Order Centroid atau disingkat ROC merupakan satu dari beberapa metode pembobotan yang cukup sederhana. Dibandingkan dengan Analytical Hierarchy Process (AHP), Entropy metode ROC cukup mudah dalam implementasinya. Kemudahan yang diberikan ROC dalam proses pemerolehan bobot kriteria yang dihasilkan[6], [16].

\subsection{Simple Additive Weighting(SAW)}

Metode Simple Additive Weighting merupakan metode yang dapat melakukan perangkingan dengan penjumlahan terbobot pada setiap nilai alternatif[16]-[18]. Metode ini cukup mudah dalam proses perhitungannya. Adapun langkah langkah dari penerapan metode SAW, yaitu:

1. Mempersiapkan matrik keputusan (Xij)

2. Menormalisasikan matrik keputusan (Rij)

3. Menghitung Preferensi (Vi) dan perangkingan

Hasil akhir dari metode SAW merupakan nilai terbaik yang diperoleh dari nilai preferensi dari alternatif yang tertinggi.

\section{ANALISA DAN PEMBAHASAN}

Proses pemberian kredit membutuhkan sistem yang dapat membantu dalam memberikan dukungan terhadap suatu keputusan untuk calon nasabah dengan cepat dan tepat. Hal ini dapat meringankan pihak Bank dalam menentukan calon nasabah yang tepat dalam pemberian Kredit. Penilaian setiap calon nasabah terhadap kriteria-kriteria yang ada dilakuan dengan model penilaian yang bersifat kuantitatif.

Salah satu metode perhitungan kuantitatif yaitu menggunakan kombinasi Rank Order Centroid dan Simple Additive Weighting. Pada tahap awal dari pemecahan permasalahan pemberian kredit, terlebih dahulu menentukan jenis-jenis kriteria pemberian kredit. Berikut kriteria yang dibutuhkan dalam pemberian kredit yang dapat dilihat pada tabel 1 .

Tabel 1. Kriteria Penilaian Kinerja

\begin{tabular}{cll}
\hline Kriteria & \multicolumn{1}{c}{ Keterangan } & Jenis \\
\hline $\mathrm{C}_{1}$ & Nilai Jaminan & Benefit \\
$\mathrm{C}_{2}$ & Penghasilan & Benefit \\
$\mathrm{C}_{3}$ & Status Tempat Tinggal & Benefit \\
$\mathrm{C}_{4}$ & Usaha & Benefit \\
\hline
\end{tabular}

Dari kriteria diatas, dilakukan pemberian terhadap nilai bobot dengan menerapkan metode Rank Order Centroid (ROC), dengan menggunakan rumus berikut:

$$
W_{m}=\frac{1}{m} \sum_{1=1}^{m}\left(\frac{1}{i}\right)
$$

Berdasarkan rumus diatas, maka perhitungan seperti dibawah ini:

$W_{1}=\frac{1+\frac{1}{2}+\frac{1}{3}+\frac{1}{4}}{4}=0.521$

$W_{2}=\frac{0+\frac{1}{2}+\frac{1}{3}+\frac{1}{4}}{4}=0.257$

$W_{3}=\frac{0+0+\frac{1}{3}+\frac{1}{4}}{4}=0,146$

$W_{4}=\frac{0+0+0+\frac{1}{4}}{4}=0,063$

Sehingga nilai bobot untuk C1 yaitu $0.521, \mathrm{C} 2$ yaitu $0.271, \mathrm{C} 3$ yaitu 0.146 dan C4 yaitu 0.063 . Berikutnya menetapkan alternatif dari calon nasabah yang mengajukan kredit, seperti terlihat pada tabel 2 berikut ini.

Tabel 2. Alternatif Calon Nasabah

\begin{tabular}{ccccc}
\hline Alternatif & $\left(\mathbf{C}_{\mathbf{1}}\right)$ & $\left(\mathbf{C}_{\mathbf{2}}\right)$ & $\left(\mathbf{C}_{\mathbf{3}}\right)$ & $\left(\mathbf{C}_{\mathbf{4}}\right)$ \\
\hline $\mathrm{A}_{1}$ & 25 Juta & 4.2 Juta & Milik Sendiri & Memiliki \\
$\mathrm{A}_{2}$ & 40 Juta & 3.5 Juta & Kontrak & Memiliki \\
\hline
\end{tabular}




\begin{tabular}{ccccc}
\hline $\mathrm{A}_{3}$ & 30 Juta & 3.1 Juta & Milik Sendiri & Memiliki \\
$\mathrm{A}_{4}$ & 25 Juta & 2.5 Juta & Keluarga & Tidak Memiliki \\
$\mathrm{A}_{5}$ & 15 Juta & 3.8 Juta & Kontrak & Memiliki \\
$\mathrm{A}_{6}$ & 20 Juta & 2.5 Juta & Keluarga & Tidak Memiliki \\
$\mathrm{A}_{7}$ & 35 Juta & 3.1 Juta & Keluarga & Memiliki \\
$\mathrm{A}_{8}$ & 32 Juta & 3.5 Juta & Keluarga & Tidak Memiliki \\
$\mathrm{A}_{9}$ & 29 Juta & 3.1 Juta & Kontrak & Memiliki \\
$\mathrm{A}_{10}$ & 29 Juta & 3.1 Juta & Kontrak & Tidak Memiliki \\
\hline
\end{tabular}

Pada tabel 2 nilai dari nilai alternatif calon karyawan akan dibobotkan pada tiap tiap kriteria baik C3 maupun C5, yang terlihat pada tabel 3 dan tabel 4.

Tabel 3. Pembobotan nilai kriteria $\mathrm{C}_{3}$

\begin{tabular}{lc}
\hline Keterangan & Bobot \\
\hline Milik Sendiri & 3 \\
Keluarga & 2 \\
Kontrak & 1 \\
\hline
\end{tabular}

Tabel 4. Pembobotan nilai kriteria $\mathrm{C}_{4}$

\begin{tabular}{lc}
\hline Keterangan & Bobot \\
\hline Memiliki & 1 \\
Tidak Memiliki & 0 \\
\hline
\end{tabular}

Rating kecocokan dapat dilihat pada tabel 5, Untuk C3 dan C4 telah dibobotkan menggunakan tabel 3dan 4.

Tabel 5. Rating Kecocokan

\begin{tabular}{ccccc}
\hline Alternatif & $\left.\mathbf{( C}_{\mathbf{1}}\right)$ & $\left.\mathbf{( C}_{\mathbf{2}}\right)$ & $\mathbf{( \mathbf { C } _ { 3 } )}$ & $\left.\mathbf{( C}_{\mathbf{4}}\right)$ \\
\hline $\mathrm{A}_{1}$ & 25 & 4.2 & 3 & 1 \\
$\mathrm{~A}_{2}$ & 40 & 3.5 & 1 & 1 \\
$\mathrm{~A}_{3}$ & 30 & 3.1 & 3 & 1 \\
$\mathrm{~A}_{4}$ & 25 & 2.5 & 2 & 0 \\
$\mathrm{~A}_{5}$ & 15 & 3.8 & 1 & 1 \\
$\mathrm{~A}_{6}$ & 20 & 2.5 & 2 & 0 \\
$\mathrm{~A}_{7}$ & 35 & 3.1 & 2 & 1 \\
$\mathrm{~A}_{8}$ & 32 & 3.5 & 2 & 0 \\
$\mathrm{~A}_{9}$ & 29 & 3.1 & 1 & 1 \\
$\mathrm{~A}_{10}$ & 29 & 3.1 & 1 & 0 \\
\hline
\end{tabular}

Penerapan Sistem Pendukung Keputusan membutuhkan data diantaranya Kriteria (tabel 1), Alternatif (tabel 2) dan nilai bobot. Pemrosesan untuk menghasilkan keputusan kemudian menerapkan metode SAW dapat dilihat pada bagian dibawah ini:

1. Mempersiapkan matrik keputusan (Xij)

Berikut merupakan matrik keputusan yang diperoleh dari tabel 5 (rating kecocokan).

Xij $\quad \begin{array}{cccc}25 & 4.2 & 3 & 1 \\ 40 & 3.5 & 1 & 1 \\ 30 & 3.1 & 3 & 1 \\ 25 & 2.5 & 2 & 0 \\ 15 & 3.8 & 1 & 1 \\ 20 & 2.5 & 2 & 0 \\ 35 & 3.1 & 2 & 1 \\ 32 & 3.5 & 2 & 0 \\ 29 & 3.1 & 1 & 1 \\ 29 & 3.1 & 1 & 0\end{array} \mid$

2. Menghitung Normalisasi Matrik (Rij) yang diproses dari matrix Xij

Perhitungan dengan jenis kriteria benefit, menggunakan persamaan berikut.

$$
R_{i j}=\frac{X_{i j}}{\operatorname{Max} X_{i j}}
$$

Perhitungan dengan jenis kriteria cost, menggunakan persamaan berikut. 


$$
R_{i j}=\frac{\operatorname{Min} X_{i j}}{X_{i j}}
$$

Hasil dari perhitungan normalisasi matrik keputusan sebagai berikut.

\begin{tabular}{c|cccc} 
& 0.63 & 1.00 & 1.00 & 1.00 \\
Rij & 1.00 & 0.83 & 0.33 & 1.00 \\
0.75 & 0.74 & 1.00 & 1.00 \\
& 0.63 & 0.60 & 0.67 & 0.00 \\
& 0.38 & 0.90 & 0.33 & 1.00 \\
0.50 & 0.60 & 0.67 & 0.00 \\
& 0.88 & 0.74 & 0.67 & 1.00 \\
0.80 & 0.83 & 0.67 & 0.00 \\
0.73 & 0.74 & 0.33 & 1.00 \\
& 0.73 & 0.74 & 0.33 & 0.00
\end{tabular}

Berikutnya menentukan Preferensi dengan menggunakan persamaan 4.

$$
V_{i}=\sum_{j=1}^{n} W_{j} \cdot R_{i j}
$$

Hasil dari penentuan preferensi menggunakan persamaan 4, diperoleh pada tabel 6 .

Tabel 6. Penentuan Preferensi

\begin{tabular}{cc}
\hline Alternatif & Nilai Vi \\
\hline $\mathrm{A}_{2}$ & 0.858 \\
$\mathrm{~A}_{7}$ & 0.815 \\
$\mathrm{~A}_{1}$ & 0.805 \\
$\mathrm{~A}_{3}$ & 0.799 \\
$\mathrm{~A}_{8}$ & 0.74 \\
$\mathrm{~A}_{9}$ & 0.689 \\
$\mathrm{~A}_{10}$ & 0.626 \\
$\mathrm{~A}_{4}$ & 0.584 \\
$\mathrm{~A}_{5}$ & 0.551 \\
$\mathrm{~A}_{6}$ & 0.519 \\
\hline
\end{tabular}

Dari tabel 5 diatas, dapat dilihat preferensi akhir dari calon nasabah yang mengajukan pengajuan kredit. Hasil tersebut menunjukkan bahwa calon nasabah $\mathrm{A}_{2}$ memiliki nilai yang tertinggi dari calon nasabah lainnya dengan nilai 0.858. Dalam hal ini keputusan akhir tergantung dari manager kredit untuk memberikan keputusan akhir, siapakah calon nasabah yang terdapat dari tabel 5 yang disetujui dalam pengajuan kredit.

\section{KESIMPULAN}

Hasil penelitian terlihat bahwa penerapan sistem pendukung keputusan (SPK) dalam penilaian pemberian kredit bagi calon nasabah yang mengajukan kredit dapat menghasilkan keputusan baik dan terbebas dari penilaian subjektifitas manager. Dalam hal ini SPK dapat memberikan hasil akhir yang diinginkan manager kredit, nampun keputusan akhir tetap di tangan manager kredit karena SPK pada dasarnya membantu dalam menghasilkan keputusan, bukan mutlak hasil yang diberikan dapat mengubah keputusan manager.

\section{REFERENCES}

[1] E. Turban, J. E. Aronson, and T. Liang, "Decision Support Systems and Intelligent Systems."

[2] S. Kusumadewi, S. Hartati, A. Harjoko, and R. Wardoyo, Fuzzy Multi-Attribute Decision Making (Fuzzy MADM). Yogyakarta: Graha Ilmu, 2006.

[3] D. Nofriansyah and S. Defit, Multi Criteria Decision Making (MCDM) pada Sistem Pendukung Keputusan. 2018.

[4] Kusrini, Konsep dan Aplikasi Sistem Pendukung Keputusan. 2007.

[5] I. Saputra, S. I. Sari, and Mesran, "PENERAPAN ELIMINATION AND CHOICE TRANSLATION REALITY ( ELECTRE ) DALAM PENENTUAN KULKAS TERBAIK,” KOMIK (Konferensi Nas. Teknol. Inf. dan Komputer), vol. I, pp. $295-305,2017$.

[6] Mesran, J. Afriany, and S. H. Sahir, "Efektifitas Penilaian Kinerja Karyawan Dalam Peningkatan Motivasi Kerja Menerapkan Metode Rank Order Centroid (ROC) dan Additive Ratio Assessment (ARAS)," in Seminar Nasional Riset Information Science (SENARIS), 2019, no. September, pp. 813-821.

[7] Khairul;, M. Simaremare, A. Putera, and U. Siahaan, "Decision Support System in Selecting The Appropriate Laptop Using Simple Additive Weighting," Int. J. Recent TRENDS Eng. Res., vol. 2, no. 12, pp. 215-222, 2016.

[8] T. widodo Nuri Guntur Perdana, "Sistem Pendukung Keputusan Pemberian Beasiswa Kepada Peserta Didik Baru Menggunakan Metode TOPSIS," in Semantik, 2013, vol. 2013, no. November, pp. 1-8.

[9] Rusdiansyah, "Analisis Keputusan Menentukan Jurusan Pada Sekolah Menengah Kejuruan Dengan Metode Simple Additive Weighting," Teh. Nusa Mandiri, vol. XIV, no. 1, pp. 49-56, 2017. 
[10] M. Mesran, R. Rusiana, and M. Sianturi, "Decision Support System for Termination of Employment using Elimination and Choice Translation Reality Method," J. Teknol. dan Sist. Komput., vol. 6, no. 4, p. 135, 2018

[11] D. Assrani, Mesran, R. D. Sianturi, Yuhandri, and A. Iskandar, "KOMIK (Konferensi Nasional Teknologi Informasi dan Komputer) SISTEM PENDUKUNG KEPUTUSAN PEMILIHAN GURU PRODUKTIF PESERTA PELATIHAN ASESOR KOMPETENSI LSP P1 SMK SWASTA DWIWARNA MEDAN MENGGUNAKAN METODE THE EXTENDED PROMETHEE II (EXPROM II)," KOMIK (Konferensi Nas. Teknol. Inf. dan Komputer), vol. 2, 2017.

[12] M. Mesran, S. D. Nasution, S. Syahputra, A. Karim, and E. Purba, "Implementation of the Extended Promethee II in Upgrade Level of Mechanic," Int. J. Sci. Res. Sci. Technol., vol. 4, no. 2, pp. 125-130, 2018.

[13] W. Bengal, W. Bengal, and W. Bengal, "A comparative study of preference dominance-based approaches for selection of industrial robots," Adv. Prod. Eng. Manag., vol. 9, no. 1, pp. 5-20, 2014.

[14] H. Nurdiyanto and Heryanita Meilia, "SISTEM PENDUKUNG KEPUTUSAN PENENTUAN PRIORITAS PENGEMBANGAN INDUSTRI KECIL DAN MENENGAH DI LAMPUNG TENGAH MENGGUNAKAN ANALITICAL HIERARCHY PROCESS (AHP)," in Seminar Nasional Teknologi Informasi dan Multimedia 2016, 2016, no. February, pp. 1-7.

[15] S. Chakraborty, "Applications of the MOORA method for decision making in manufacturing environment," Int. J. Adv. Manuf. Technol., vol. 54, no. 9-12, pp. 1155-1166, 2011.

[16] R. T. Utami, D. Andreswari, and Y. Setiawan, "Implementasi Metode Simple Additive Weighting (SAW) dengan pembobotan Rank Order Centroid(ROC) Dalam Pengambilan Keputusan Untuk Seleksi Jasa Leasing Mobil," J. Rekursif, vol. 4, no. 2, pp. 209-221, 2016.

[17] S. H. Sahir, R. Rosmawati, and K. Minan, "Simple Additive Weighting Method to Determining Employee Salary Increase Rate," Int. J. Sci. Res. Sci. Technol., vol. 3, no. 8, pp. 42-48, 2017.

[18] M. D. L. Siahaan, Elviwani, A. B. Surbakti, A. H. Lubis, and A. P. U. Siahaan, "Implementation of Simple Additive Weighting Algorithm in Particular Instance,” Int. J. Sci. Res. Sci. Technol., vol. 3, no. 6, pp. 442-447, 2017. 